\title{
Feeding practice during the first two years of life in a group of infants attending a health care centre in the La Chorrera city of Panama
}

\author{
C. Hogan ${ }^{1}$, J. Kearney ${ }^{1}$ and O. Bermudez ${ }^{2}$ \\ ${ }^{1}$ Dublin Institute of Technology, Kevin Street, Dublin 8, Republic of Ireland and ${ }^{2}$ Department of Public Health and \\ Community Medicine, Tufts University School of Medicine, 136 Harrison Avenue, Boston, MA 02111, USA
}

Little awareness regarding the importance of 'The First 1000 Days' exists in Panama and has not gained coverage either among health care professionals or the mass media. Infant feeding during this period is a 'window of opportunity' not to be overlooked as nutrition in this period impacts on both the immediate and future health of the child in relation to infectious diseases ${ }^{(1)}$ and chronic disease ${ }^{(2)}$. The World Health Organisation recommends exclusive breastfeeding for the first six months of life with adequate complementary feeding introduced thereafter ${ }^{(3)}$. If all children in the developing world received adequate nutrition and feeding of solid foods with breastfeeding, stunting rates at 12 months could be cut by 20 percent $^{(1)}$.

This explorative study looks at aspects of infant feeding practice in a group $(n=100)$ of health children from 6 months to two years of age attending a health care centre in La Chorrera, Panama. In order to assess infant feeding practice a short questionnaire containing both open and closed questions was administered among willing mothers.

The mean age of infants in the study was $10 \cdot 1$ months. $90 \%$ of women initiated breastfeeding, very similar to the $91 \%$ reported in $1984-1985^{(4)} .26 \%$ of mothers chose exclusive breastfeeding (EBF) for six months; also representative of $27 \cdot 5 \%$ reported in $2009^{(5)}$. $57 \%$ of mothers continued to breastfeed their child beyond six months. $41 \%$ of mothers chose to breastfeed as they considered it important for their child's health, with 'helping to protect their child from illness as the most frequently reported benefit of EBF while $7 \%$ reported that they were not aware of the benefits of EBF. In $49 \%$ of cases, 'work' was the reason given for discontinuation of EBF prior to six months, however only $28 \%$ of mothers were currently employed. $57 \%$ of infants began weaning at six months; the most frequent first weaning food was in the 'other' category $(28 \%)$ which mothers frequently reported as soup, followed closely by fruit purée $(26 \%)$. As sources of iron and protein included in the diet at a later stage, $82 \%$ of children were eating meat/fish/chicken, $76 \%$ lentils/beans and 79\% were eating eggs, suggesting an adequate diet among those that have started weaning. From 6 months of age $75 \%$ of infants were reported as capable of drinking from a cup independently.

The outcomes of this study offers the potential for future emphasis on the importance of nutrition in the first 1000 days, particularly in relation to the importance of exclusive breastfeeding as it is lower than the international average of $36 \%{ }^{(6)}$. Furthermore, further research on the factors influencing breastfeeding decisions and a more in depth investigation of the weaning diet would provide information that could inform campaigns to encourage mothers to adopt optimal infant feeding practices.

1. Save the Children. State of the World's Mothers 2012. Brookstone: New Hampshire, 2012.

2. Barker DJP. Developmental origins of chronic disease. Public Health 2012; 126(3): 185 189. doi: http://dx.doi.org/10.1016/j.puhe.2011.11.014

3. World Health Organisation. Fact File: 10 Facts of Breastfeeding. Available from: http://www.who.int/features/factfiles/breastfeeding/facts/en/ Accessed: $14 / 03 / 14$

4. Huffman S. Panama Breastfeeding Promotion Project Evaluation. Available from: http://pdf.usaid.gov/pdf docs/PDABA439.pdf. Accessed: $17 / 03 / 14$

5. World Health Organisation and Pan American Health Organisation. World Breastfeeding Week 2013 Breastfeeding Support: Close to Mothers. Available from: file:///C:/Users/owner/Downloads/wbw13_brochure_eng\%20(1).pdf, 2013. Accessed: 17/03/14

6. World Health Organisation. Proposed global targers for maternal, infant and young child nutrition (Discussion Paper). Available from: http://www. who.int/nutrition/events/2012_proposed_globaltargets_backgroundpaper.pdf, 2012. Accessed: 17/03/14 